ALPHA No 29 Diciembre 2009 (143-154)

ISSN 0716-4254

http://alpha.ulagos.cl

\title{
EQUÍVOCOS DEL LENGUAJE: HOMOEROTISMO EN LUGAR DE HOMOSEXUALIDAD
}

Misunderstandings of language: homoeroticism in the place of homosexuality

Juan Cornejo Espejo*

\section{Resumen}

La denominación "homosexual" u "homosexualismo" nos remite a una conceptualización y representación de las prácticas sexuales homogenitales como patológicas, perversas y/o desviadas. Varios autores prefieren la noción "homoerotismo” por la mayor claridad de este término, pues describe mejor la pluralidad de prácticas y deseos de los hombres orientados hacia el mismo sexo. El homoerotismo aleja la posibilidad de asociación con enfermedad, desvío, anormalidad o perversión. Niega la idea de que exista algo como una "substancia homosexual" orgánica o psíquica común a todos los hombres con tendencias homoeróticas. Además, el témino no posee una forma sustantivada que indique identidad, como en el caso del homosexualismo.

Palabras clave: Homosexualidad, homoerotismo, lenguaje, naturalización.

\begin{abstract}
The denomination "homosexual" or "homosexualism" remit us to the conception and representation of homogenital sexual practices as pathological, perverse, and diverted. Many authors prefer the notion of "homoeroticism" because of the major clarity of this term, since it better describes the plurality of practices and wishes of men oriented towards the same sex. Homoeroticism moves away from the possibility of association with illness, divergence, anormality or pervertion. It denies the idea that there exists something like a "homosexual substance," organic or psychiatric, that is common to all men with homoerotic tendencies. Moreover, the term does not have a noun form which indicates identity, as is the case of homosexualism.
\end{abstract}

Key words: Homosexuality, homoeroticism, language, naturalization.

\section{CONCEPTUALIZACIÓN Y REPRESENTACIÓN}

Los homosexuales constantemente son identificados por sus preferencias sexuales, las cuales a su vez son moralmente desaprobadas en virtud de la calidad de patología que le asignó la medicina psiquiátrica, o aun el psicoanálisis. La presentación de ciertas prácticas sexuales como anormales, patológicas, antinaturales o moralmente incorrectas no hace sino estigmatizar y 


\section{Juan Cornejo Espejo}

discriminar a numerosos sujetos que se apartan de los ideales sexuales de la mayoría. De allí que criticar la creencia discriminatoria implica criticar, también, el vocabulario que permite su enunciación y que lo torna razonable a los oídos de los receptores. Concretamente, la denominación "homosexual" u "homosexualismo" no hace sino remitirnos a una conceptualización y representación de las prácticas sexuales homogenitales como patológicas, perversas y/o desviadas.

En vista de ello, varios autores prefieren la noción "homoerotismo". ${ }^{1}$ En primer lugar, por la mayor claridad de este término, pues describe mejor la pluralidad de prácticas y deseos de los hombres orientados hacia el mismo sexo. A juicio de estos autores, interpretar la idea de "homosexualidad" como una esencia, una estructura o denominador sexual común a todos los hombres con tendencias homoeróticas es incurrir en un heterosexismo inaceptable. El homoerotismo, en cambio, aleja la posibilidad de asociación con enfermedad, desvío, anormalidad o perversión. En segundo lugar, niega la idea de que exista algo como una "substancia homosexual” orgánica o psíquica común a todos los hombres con tendencias homoeróticas. En tercer lugar, porque el término no posee una forma sustantivada que indique identidad, como en el caso del homosexualismo, de donde se derivó el sustantivo homosexual. ${ }^{2}$

En esta misma línea, Michel Foucault critica la idea de que pueda interpretarse la homosexualidad como una "constante antropológica”, e insiste en el hecho de que no hay permanencia a través de los siglos de aquello que designamos con ese término (1994:315-317). Es más, en su Historia de la Sexualidad, describe la invención que, a finales del siglo XIX, hace el discurso psiquiátrico del homosexual (2002:36-37). Antes de esta fecha, dice, sólo había "actos" condenables; después endosaron, a quienes los practicaban, una "psicología”, sentimientos, una infancia, etc. Foucault se convirtió, así, en el antídoto a la tesis de John Boswell (1992) y de su concepción "esencialista" de la historia homosexual. Sus escritos se constituyeron en punto de referencia obligado de los historiadores "construccionistas" que niegan toda posibilidad de que exista una suerte de "substancia homosexual" como la formulada por Boswell.

\footnotetext{
${ }^{1}$ Cfr. Kenneth Lewes. The Psychoanalytic theory of male homosexuality (1989); Robert Stoller. Sexual Excitement (1979); Observing the eroting imagination (1987) e Intimate Communications - erotics and the study of culture (1989); Jurandir Freire Costa. A inocência e $o$ vício. Estudo sobre o homoerotismo (1992) y A face e o verso. Estudo sobre o homoerotismo II (1995).

2 Adrienne Rich sostiene una postura crítica, análoga, respecto de la adjetivación de que es objeto la palabra lesbiana. No obstante, su crítica no se reduce a la adjetivación sino, también, a la homologación con la homosexualidad (1980:188-189).
} 


\section{Equívocos del lenguaje: Homoerotismo en lugar de homosexualidad}

Un aspecto estrechamente vinculado con la construcción del sujeto homosexual es el tema de la injuria. Esta, según señalan los teóricos de los estudios gay-lésbicos, antecede al sujeto, aun antes de su propia existencia. Y puesto que la ideología precede al nacimiento de los individuos a quienes interpela, Louis Althusser llega a decir: "La ideología ya ha interpelado siempre a los individuos como sujetos. Los individuos incluso antes de nacer y, por ende, desde su nacimiento, son "siempre-ya" sujetos constituidos por la ideología que modela el mundo al que llegan” (1976:113-114).

Así, el insulto y sus efectos no son más que la parte visible de la interpelación más profunda, cuyo origen se remonta a las estructuras sociales, mentales y sexuales existentes que operan sobre el sujeto. El orden social y sexual cuyo vínculo es el lenguaje-y uno de cuyos síntomas más agudos es la injuria - produce, al mismo tiempo, el sujeto como subjetividad y como sujeción, es decir, como una persona adaptada a las reglas y a las jerarquías socialmente instituidas. La subjetividad gay es, pues, una subjetividad "inferiorizada” no sólo porque encuentra la situación inferior creada para los homosexuales en la sociedad, sino, sobre todo, porque está producida por ésta. Dicho de otro modo, el sujeto es producido por la interpelación, o sea, por las estructuras cognitivas y, por ende, sociales de las que es el vector (Eribón, 2001:88).

En este mismo plano cabe subrayar que el lenguaje cotidiano está atravesado por relaciones sociales (de clase, de sexo, de edad, de raza, etc.) y es en y por el lenguaje como se ejerce la dominación simbólica, es decir, la definición y la imposición de las percepciones del mundo y de las representaciones socialmente legitimadas. El dominante, como dice Pierre Bourdieu, es el que consigue imponer la manera en que quiere ser percibido, en tanto que el dominado es definido, pensado y hablado por el lenguaje del otro, o ese que no logra imponer la percepción que tiene de sí mismo. "Los dominados aplican categorías construidas desde el punto de vista de los dominantes a las relaciones de dominación, y así las hacen parecer naturales” (Bourdieu, 2000: 40). Ahora bien, la fuerza de esta representación reside en que es presentada dentro de un supuesto orden natural, inmutable, y sobre el cual no se interroga o se interroga falsamente para mejor reafirmarlo. ${ }^{3}$ De allí que la movilización y acción política sean siempre batallas por la representación, el lenguaje y las palabras.

${ }^{3}$ En este punto cabría señalar que, como lo han hecho notar los críticos de Bourdieu, los dominados no estarían irremediablemente condenados a una pasividad absoluta, como parece desprenderse de sus afirmaciones, creando en algunos casos mecanismos de resistencia a dicha dominación. 


\section{Juan Cornejo Espejo}

Se puede afirmar, entonces, que el "hombre homosexual” no es más que una realidad lingüística y no, como se sostiene muchas veces, una realidad natural. Es una forma de subjetividad que como cualquier subjetividad puede ser históricamente circunscrita en su modo de expresión y de reconocimiento. Nuestra época hizo de la homosexualidad una "realidad psíquica y sexual”, que se nos presenta como un modo de ser del sujeto, natural y universalmente necesaria y no culturalmente construida y arbitraria (Costa, 1992:23).

Es más, esta concepción ha hecho que muchos homosexuales se conciban y representen según esas categorías. En este sentido, es importante insistir que la subjetividad homosexual está dominada por los modos de representación heterosexuales y por la violencia normativa que ejercen estos modos. Al homosexual se le remite siempre a la norma, incluso cuando son los propios homosexuales los que hablan (Eribón, 2001:124-125).

\section{VENTAJAS DE LA NOCIÓN: "HOMOEROTISMO”}

Presentar ciertas prácticas sexuales como anormales, enfermizas, antinaturales o moralmente reprobables implica, entre otras cosas, que esa reprobación está instalada en el lenguaje. De allí que criticar la creencia discriminatoria significa, también, criticar el vocablo que hace posible su enunciación y, a su vez, la torna razonable.

Por otro lado, al usar en nuestro lenguaje ordinario el sustantivo "homosexual" terminamos rehenes de nuestros hábitos. El empleo frecuente del término lleva a creer que realmente existe un tipo humano específico designado por ese sustantivo común. Todavía más, creemos que la peculiaridad presentada por ese tipo es una propiedad permanente de la naturaleza de ciertos hombres, independientemente de las descripciones que la tornan visible y plausible a nuestros hábitos lingüísticos; o sea, es una cualidad de ciertos humanos que antecede los vocabularios responsables por la invención del término "homosexual" y del supuesto tipo de hombre que le corresponde. En vista de ello no hay por qué sustituir el término "homosexual" por un sustantivo homólogo derivado de homoerotismo. Semejante creación nos haría creer que existe "algo común a todos los homosexuales" fuera de aquello que nuestra práctica lingüística nos habituó a ver e interpretar "como lo que existe en común” entre todos los sujetos homoeróticamente inclinados.

Siendo esto así, cuando se emplea la palabra "homoerotismo" se alude a la posibilidad que tienen ciertos sujetos de sentir diversos tipos de atracción erótica o de relacionarse físicamente de diversas maneras con otros del mismo sexo biológico. En otras palabras, el homosexual no es, como solemos creer, alguien que posee un conjunto de trazos psíquicos que determinarían la inevitable 
y necesaria expresión de la sexualidad homoerótica en quien quiera que las poseyese (Costa, 1993:22).

La particularidad del homoerotismo en nuestra cultura no se debe a la uniformidad psíquica de la estructura del deseo común a todos los homosexuales. Se debe, más bien, a que es una experiencia subjetiva moralmente desaprobada por el ideal sexual de la mayoría. Afirmar esto en una cultura como la nuestra, orientada a la idea de realización afectiva y sexual, es privar a ciertos sujetos de esa realización. Tanto más cuando esos mismos sujetos fueron enseñados a desear ese tipo de satisfacción. Convivir con esa paradoja emocional exige un montaje imaginario en que ciertas defensas psíquicas son recurrentes, por cuanto se muestran eficientes en la protección contra el prejuicio.

No obstante, el uso del vocablo homoerotismo escogido por su mayor neutralidad moral si lo comparamos con el término homosexualidad debe ser visto como táctica argumentativa y no como proposición conceptual con pretensiones de validez universal. Mejor aún, el empleo del término homoerotismo pretende distanciar al interlocutor de la noción de "homosexualidad”, pues una cierta familiaridad entre ambos términos podría interpretarse como una nueva revalidación moral del "homosexualismo".

\section{EL “HOMBRE HOMOSEXUAL”: UNA REALIDAD LINGÜÍSTICA}

Es preciso afirmar que el "hombre homosexual" no es más que una realidad lingüística y no una realidad natural. Es una forma de subjetividad que como cualquier otra puede ser históricamente circunscrita en su modo de expresión y de reconocimiento. En épocas pasadas otras creencias lingüísticas confirieron foros de realidad natural o universal a ciertas formas de subjetivación, al igual como en nuestro tiempo lo hemos hecho con la "homosexualidad”. Es decir, una supuesta "realidad psíquica y sexual” que nos aparece como un modo de ser del sujeto, natural y universalmente necesario y no culturalmente arbitrario.

En vista de lo anterior es preciso reiterar que el empleo de la noción homoerotismo no es un nuevo nombre para denominar una misma y vieja realidad existencial: la "realidad homosexual". Tampoco pretendemos afirmar que el homoerotismo es un concepto que en su transparencia racional exhibe la verdadera realidad psíquica y moral del homosexualismo.

Además, el uso de homoerotismo tiene ventajas de orden histórico, pues el término "homosexual” está excesivamente comprometido con el contexto médico legal, psiquiátrico, sexológico e higienista que es de donde surgió. El "homosexual" fue un personaje imaginario cuya función era ser la antinomia ideal de la masculinidad requerido por la familia burguesa decimonónica. Así, 


\section{Juan Cornejo Espejo}

siempre que la palabra es usada se evoca el contexto de creencias prejuiciadas que hasta nuestros días divide naturalmente a los hombres entre "homosexuales” y “heterosexuales" (Costa, 1993:23-24).

No obstante, se podría objetar que no todas las personas que recurren al término "homosexual" son prejuiciosas, comenzando por los propios homosexuales, que no disponen en el lenguaje corriente de otro término para referirse a la identidad socio-sexual que asumieron. Sin embargo, cuando afirmamos que la palabra "homosexualismo" u "homosexual” está subordinada al contexto discriminatorio en que aparece, eso no depende de la intención de los hablantes.

Con la introducción del término homoerotismo, tomado de Sandor Ferenczi (1970) y que contó con la aprobación de Freud (1988), se pretende señalar algunos aspectos que permanecen ocultos por cuanto se insiste en usar las nociones de "homosexualismo", "homosexual" u "homosexualidad". Al admitir la dicotomía entre "homosexual"/“heterosexual" subrayamos las características sexuales de los sujetos; además, tal dicotomía no tiene nada de espontánea. Ninguna división de las personas en clases lógicas, familias naturales o conjuntos gestálticos es natural. Todos esos rangos exigen una selección de predicados relevantes para ciertos intereses, que son tan antinaturales cuanto cualquier constructo teórico que podamos imaginar.

De este modo, por ejemplo, cuando constatamos que en ciertas sociedades históricas o etnológicas sería totalmente impensable distribuir los sujetos en "homosexuales" y "heterosexuales", tendemos a creer que es una excepción, pues, "naturalmente” percibimos la división como "natural”. En este sentido podemos afirmar que la excepción es sólo "excepcional” desde el punto de vista de quien está fuera. En sociedades donde el homoerotismo era tan o más difundido que el heteroerotismo, excepcional era no adoptar tales valores.

\section{HOMOEROTISMO Y CONTEXTO HISTÓRICO}

Si pensamos lo anterior en el contexto de la antigüedad clásica, cabría señalar que los griegos eran "pederastas" y no "homosexuales", pues la pederastia como el "homosexualismo" son dos formas de cristalización del imaginario cultural sobre la potencialidad homoerótica y no dos nombres para un mismo referente. Todavía más, toda vez que pensamos en las relaciones eróticas entre hombres no las relacionamos con los grandes personajes históricos que las mantuvieron regularmente, puesto que esas imágenes de homoerotismo contradicen nuestros esquemas cognitivos o, psicoanalíticamente hablando, nuestras imágenes narcísicas proyectadas en nuestros ideales morales.

Para nuestra sociedad, homoerotismo es sinónimo de pusilanimidad y de afeminamiento; no de la virilidad o masculinidad de los personajes legen- 
darios que están en los orígenes míticos de la civilización occidental de la que hacemos parte, razón por la cual es casi imposible para nuestros hábitos lingüísticos asociarlos a las prácticas homoeróticas.

A pesar de esa resistencia afectiva e intelectual, es innegable que estos hombres cultivaron, según la expresión de Peter Gay (1992), "los amores masculinos", al igual como cultivaron el "amor heterosexual romántico"; es decir, erigieron sus amores como modelo de felicidad afectivo-sexual.

Además de la excepción, otro argumento recurrente para deslegitimar las prácticas homoeróticas es el de la ignorancia. Los antiguos ya sea que fueran civilizados o primitivos, se señala, eran homosexuales que ignoraban su homosexualidad. Por el hecho de no contar con el vocabulario científico de que hoy disponemos eran incapaces de describir correctamente la verdadera naturaleza de sus inclinaciones sexuales. No obstante, este argumento plantea algunas interrogantes. Si de hecho todos aquellos hombres eran "homosexuales” sin saberlo ¿Por qué alababan con tanta vehemencia prácticas que hoy se reprueban? ¿Es que ellos eran especialmente propensos al "vicio" y a la “inmoralidad”? ¿Es que habría que pensar que la severa pedagogía griega y su rígida ética pederástica, como muestran Boswell (1992) y Dover (1989) incentivaban la perversión y la indecencia? ¿O tenían un patrimonio genético diverso al nuestro, como postulan algunos partidarios de la teoría de los genes específicos de la homosexualidad? Ciertamente, los argumentos esgrimidos evidencian sus inconsistencias al desconocer que el homoerotismo es una cuestión de prácticas lingüísticas. No existe objeto sexual "instintivamente adecuado al deseo" o, viceversa, como postula el psicoanálisis. Todo objeto de deseo es producto del lenguaje que se orienta en vista de lo que "es digno de ser deseado" y de lo que "debe ser despreciado" o considerado indiferente, como incapaz de despertar excitación erótica (Costa, 1993:28).

\section{ENTORNO CULTURAL Y COMPORTAMIENTO}

Considerando los antecedentes anteriores se puede afirmar que la aprobación cultural del homoerotismo no demuestra que todos los sujetos pueden ser "homosexuales" o "heterosexuales". Demuestra, apenas, que la mayoría de nosotros puede "comportarse homosexualmente o heterosexualmente". Ello, sin embargo, no implica que no podamos distinguir entre los "verdaderos homosexuales" de los "homosexuales ocasionales". Del mismo modo, como en una cultura heterosexual dominante muchos homosexuales se comportan como heterosexuales sin serlo, así también en culturas mayoritariamente homoeróticas muchos heterosexuales se comportan "homosexualmente" sin serlo. Por otro lado, los "verdaderos homosexuales" serían 


\section{Juan Cornejo Espejo}

aquellos que, con o sin estímulo moral de la cultura, se sentirían más atraídos por hombres que por mujeres.

Es importante tener presente que ese mito adámico de la "homosexualidad natural”, previo a cualquier "invención cultural”, es un mito retrospectivo; un mito creado para proporcionar un fundamento con apariencia de objetividad. En este sentido, el sentimiento de racionalidad o de plausibilidad que él inspira no proviene de su objetividad factual o teórica, sino de la verosimilitud que le es dada por el cuerpo de creencias que lo sustentan y permanentemente se ve obligado a reforzar.

No obstante, el mito no es admisible por varios motivos. En primer lugar, no conocemos hasta ahora ningún criterio público neutro u objetivo para decir que alguien es o no "un verdadero homosexual". No existe esa pretendida posición epistémica privilegiada donde podamos identificar al "verdadero homosexual" sin tener que recurrir a solicitudes de principios o circularidades de raciocinios cuidadosamente escondidas.

Dado el reduccionismo que impone el binomio "homosexualidad"/ "heterosexualidad", pareciera que los sujetos se ven impelidos, obligatoriamente, a optar por una de esas definiciones. Una respuesta simplista optaría por señalar que son homosexuales aquellos que se sienten atraídos por personas del mismo sexo. Con todo, esta es una respuesta ingenua, ya que supone que existe una atracción única, uniforme y suficiente para definir la identidad sexual, social y moral de una persona.

Lo que interesa no es la esencia de la atracción; sí, el objeto que define su cualidad. Cuando se habla de una "atracción homosexual" se está queriendo decir que estamos frente a una "atracción por una persona del mismo sexo”. Sin embargo, nuevamente aquí reaparece la simplificación de la respuesta que se toca con serias objeciones del lenguaje. El problema se plantea cuando intentamos definir lo que se entiende por "mismo sexo", pues para un sujeto puede ser la atracción por los genitales u otras partes físicas de otro hombre; en cambio, para otro "mismo sexo" es el objeto de amor. Más aún, "mismo sexo" para un trabajador sexual que sólo mantiene relaciones sexuales por dinero con otro hombre no tiene la misma significación que para aquel otro donde hay un envolvimiento emocional.

Se concluye entonces que "mismo sexo" — entendido como misma realidad anatómica - no es garantía por sí sola de la identidad presumiblemente de todos los "verdaderos homosexuales", pues un mismo sexo anatómico puede ser soporte de diversas inversiones eróticas. Es decir, tomar el mismo sexo anatómico como criterio para deducir la irreductibilidad de la "atracción" que definiría al "verdadero homosexual" —o al "verdadero deseo homosexual" - es reforzar la división sociocultural del binomio "homosexualidad”/“heterosexualidad”, colocándola como premisa no sometida a análisis. 
Equívocos del lenguaje: Homoerotismo en lugar de homosexualidad

Pareciera ser que cuando se habla de "verdadera homosexualidad" o de "verdadera atracción homosexual", la imagen evocada es la del amor romántico o del enamoramiento heterosexual, donde el acento está puesto en el deseo, en la "atracción” y no en el comportamiento. Forma parte del imaginario sexual-amoroso de la burguesía del siglo XIX entender que la verdad de un sentimiento está en su profundidad e intimidad psicológica. Así, el "verdadero homosexual" sería aquel que encarna el ideal del erotismo romántico, sólo que orientado hacia personas de su mismo sexo. En consideración a lo anterior, pareciera —más bien — que el "Adán homosexual" del mito de la "homosexualidad natural” es un "Adán romántico" que aprendió que hay reglas de intensidad, calidad, exclusividad, etc., en ciertas experiencias "homosexuales" que las tornan más verdaderas o más fidedignas cuando son comparadas con otras. Sin embargo, lo implícito está justamente allí. La medida de la comparación para evaluar el "tenor de la homosexualidad” de tal o cual experiencia homoerótica introduce, ella misma, el interés por una especificación que no tendría sentido en una cultura que no tuviese previamente distribuidos los sujetos en "homosexuales" y "heterosexuales".

Saber lo que es un "verdadero homosexual" sería una cuestión que un griego jamás se preguntaría, pues la distinción binominal es algo que no hacía parte de la moral antigua. En el siglo XIX, sin embargo, ella comenzó a surgir con el propósito de que los médicos, sexólogos, psiquiatras, juristas, etc. pudiesen distinguir — de entre los "homosexuales" — quién era un "verdadero homosexual", un "verdadero pervertido", un "invertido simple” sin más señales que la degeneración; un "vicioso" o un "obsceno" que aún no siendo un "verdadero homosexual" practicaba el "homosexualismo" por el gusto de la depravación. Esas distinciones, en verdad, nada tenían de teóricas. Eran cuestiones jurídico-legales y trataban de los límites histórico-sociales del ideario burgués, entonces triunfante y en pleno apogeo.

La preocupación por la "verdadera homosexualidad", en la versión "adámica” del "homosexualismo natural", refleja la obsesión por las ideologías instintivas, evolucionistas y racistas del siglo XIX para justificar el modelo de sexualidad familiar, conyugal y heterosexual, en cuanto fortaleza de la moral privada y signo de superioridad de la cultura burguesa frente a otras clases sociales y a los pueblos colonizados.

\section{TOLERANCIA Y HOMOEROTISMO}

Desde el momento en que se asume que el "homosexualismo" no es una enfermedad, una perversión o una inmoralidad, sino un fenómeno tan corriente cuanto cualquier otro fenómeno sexual, en ese momento, sin lugar a dudas, se ha ganado una gran batalla contra la intolerancia y la discriminación. En el siglo XIX, como a inicios del siglo XX, los esfuerzos de los 


\section{Juan Cornejo Espejo}

literatos, moralistas, filósofos, médicos, juristas, sexólogos, políticos, etc., por convencer a Occidente de que la "homosexualidad" no era más que una pura y simple variación del instinto sexual, fueron en vano. ${ }^{4}$

La gran ilusión (o desilusión) de hoy, como lo fue en aquel entonces, es la de acreditarlo en la fuerza persuasiva de los argumentos científicos o científicamente fundados. Nadie abandona sus creencias "prejuiciosas" porque otro puede "probarle" que aquello que piensa sobre tal o cual asunto es científicamente errado. Peor aún, se alega que "es equivocado pensar así porque contradice la concepción científica de la naturaleza”. La verdad es que si el argumento fuese eficiente no habría racismo en el mundo. Cada sistema de creencias tiene sus dispositivos que justifican y legitiman la imagen del ser humano y del mundo que se tiene.

Por tanto, resulta inoficioso e inútil intentar convertir la palabra "homosexual" en un vocablo sin residuos prejuiciosos, reafirmando la naturalidad de las tendencias homoeróticas. Es más, emplear el término como sinónimo de denominador sexual común a todas las posibilidades de atracción homoerótica es un equívoco. Como también lo es afirmar la existencia de una tendencia natural de una minoría de hombres a ser, siempre en cualquier circunstancia, ejemplar de una "misma variación natural de homosexualismo". Continuar perpetuando tal creencia supone mantener el sistema de nominación creado para hacer del homoerotismo la contrapartida rebajada y degradada de la sexualidad heteroerótica. Parece ser que en todo lazo social marcado por el prejuicio no hay forma de escapar del dispositivo imaginario de la discriminación, conservando el sistema de nominación responsable por la identificación o fijación de los sujetos en los lugares prescritos por el dispositivo. La forma de salir de ese engranaje es deshaciéndolo y no reformándolo, conservando los términos de su definición, pues el intento por combatir el prejuicio manteniendo íntegra la creencia de que los sujetos humanos están "naturalmente divididos entre homosexuales y heterosexuales”, si no es imposible, a lo menos será extraordinariamente difícil.

Por las razones antes expuestas, intentar luchar contra el prejuicio invocando la condición natural de la "homosexualidad" encuentra su principal obstáculo en el lenguaje escogido como instrumento de lucha. Dicho de otro modo, ese lenguaje es un juego de cartas marcadas donde el discriminado es forzado a recurrir al vocabulario del discriminador para identificarse como sujeto y reivindicar la consideración moral a la que aspira. Por otro lado, no

\footnotetext{
4 Textos brillantes en cuyo trasfondo subyace esta discusión, entre otros, son los de André Gide, Journal (1899-1939) (1948); O imoralista (s/d); Se o grao não morre (1983); y Corydon (1987). Además del texto de Marcel Proust “Sodome et Gomorre”. A la recherche du temps perdu (1947).
} 
Equívocos del lenguaje: Homoerotismo en lugar de homosexualidad

basta con tomar la naturaleza como aval de esa causa. La naturaleza, conforme al prejuicio, también tiene sus deficiencias, anormalidades y desvíos. No se trata de creer que porque rechacemos hablar el lenguaje discriminador podamos transformar la realidad de las prácticas sexuales y de sus respectivos determinantes lingüísticos. No podemos cambiar nuestros comportamientos sexuales por presión de uno o de muchos como tampoco podemos "desaprender" la lengua en que aprendemos a hablar. No obstante, aun cuando no podemos "desaprender" nuestros lenguajes maternos y sexualidades maternas y paternas, podemos aprender otras lenguas. En cuanto sujetos sexuados y de lenguaje, no podemos dejar de hablar y de desear, pero en cuanto sujetos de voluntad podemos redescribir y resignificar moralmente las consecuencias de aquello que no podemos escoger.

De alguna forma, con el remontaje de nuestro vocabulario descriptivo y valorativo del homoerotismo no se pretende construir nuevas formas imaginarias de gozar con nuestras sexualidades y subjetividades. Tampoco se trata de hacer de la defensa de la libre expresión social del homoerotismo una cruzada contra las costumbres heteroeróticas de la mayoría. El gran desafío no es intentar invertir la idealización romántica y las posibilidades que ofrece el ejercicio de la sexualidad heteroeróticamente dirigida. De lo que se trata es de no pretender reeditar el engranaje perverso de la discriminación, cuyo eje gira en torno de la "persecución-culpabilización".

En síntesis, alterando el formato de nuestro vocabulario dedicado al homoerotismo, si bien no resolvemos todo el problema de la discriminación, al menos contribuimos a cuestionar viejas creencias y, con ello, solucionar aquello que sí tiene solución, dejando de lado los falsos problemas o los problemas sin sentido. Nada de la condición humana, como bien señala Hannah Arendt (1993), es más frágil y “más humano" que aquello sustentado por la práctica del discurso. Así, la responsabilidad para con aquello que decimos y enseñamos a decir es uno de esos valores cuya única garantía es la confianza depositada en la palabra del otro.

$$
\begin{array}{r}
\text { Universidad de Santiago de Chile* } \\
\text { Facultad de Humanidades } \\
\text { Alameda 3363, Estación Central, Santiago (Chile) } \\
\text { jcornejoespejo@yahoo.es }
\end{array}
$$

\section{BIBLIOGRAFÍA}

ARENDT, Hannah. La condición humana. Barcelona: Paidós.

ALTHUSSER, Louis. Ideología y aparatos ideológicos de Estado. Posiciones. Barcelona: Anagrama, 1976. 
Juan Cornejo Espejo

BOSWELL, John. Cristianismo, tolerancia social y homosexualidad: los gays en Europa occidental desde el comienzo de la era cristiana hasta el siglo XIV. Barcelona: Muchnik, 1992.

BOURDIEU, Pierre. La dominación masculina. Barcelona: Anagrama, 2000.

COSTA, Jurandir Freire. Face e o verso. Estudo sobre o homoerotismo II. São Paulo: Escuta Ltda., 1995.

------- A inocencia e o vício-estudo sobre o homoerotismo. Rio de Janeiro: Relume Dumará, 1993.

DOVER, Kenneth. Greek Homosexuality. Cambridge-Mass: Harvard University, 1989.

ERIBÓN, Didier. Reflexiones sobre la cuestión gay. Barcelona: Anagrama, 2001.

FERENCZI, Sandor. "L'homoérotisme: nostalgie de l'homosexualité masculine”, en Oeuvres complètes. Tomo II (1913-1919). Psychanalyse II. París: Payot, 1970.

FOUCAULT, Michel. Historia de la sexualidad. Vol. 1. La voluntad de saber. Buenos Aires: Siglo Veintiuno, 2002.

------- “Des caresses vieilles de 2.500 ans”. Libération. Reproducido en Dits et écrits. Tomo IV. París: Gallimard, 1994.

FREUD, Sigmund. Obras completas. Buenos Aires: Amorrortu, 1988.

GAY, Peter. A paixão terna. São Paulo: Compañía das letras, 1990.

GIDE, André. Corydon. París: Gallimard, 1987.

------- Se o grao não morre. Rio de Janeiro: Nova Fronteira, 1983.

------- Journal (1899-1939). París: Gallimard, 1948.

------ O imoralista. São Paulo: Círculo do Livro, s/d.

LEWES, Kenneth. The Psychoanalytic Theory of Male Homosexuality. Ontario: New American Library, 1989.

PROUST, Marcel. "Sodome et Gomorre”. A la recherche du temps perdu. Tomo II. París: Gallimard, 1947.

RICH, Adrienne. "La heterosexualidad obligatoria y la existencia lesbiana", en Signs: Journal of Women in Culture and Society 5, $\mathrm{N}^{\circ} 4$. Diciembre (1980):159-211.

STOLLER, Robert. Intimate Communications-Erotics and The Study of Culture. New York-Oxford: Columbia University Press, 1989.

------- Observing the Eroting Imagination. New Haven: Yale University Press, 1987.

Sexual Excitement. New York: Touchstone, 1979. 